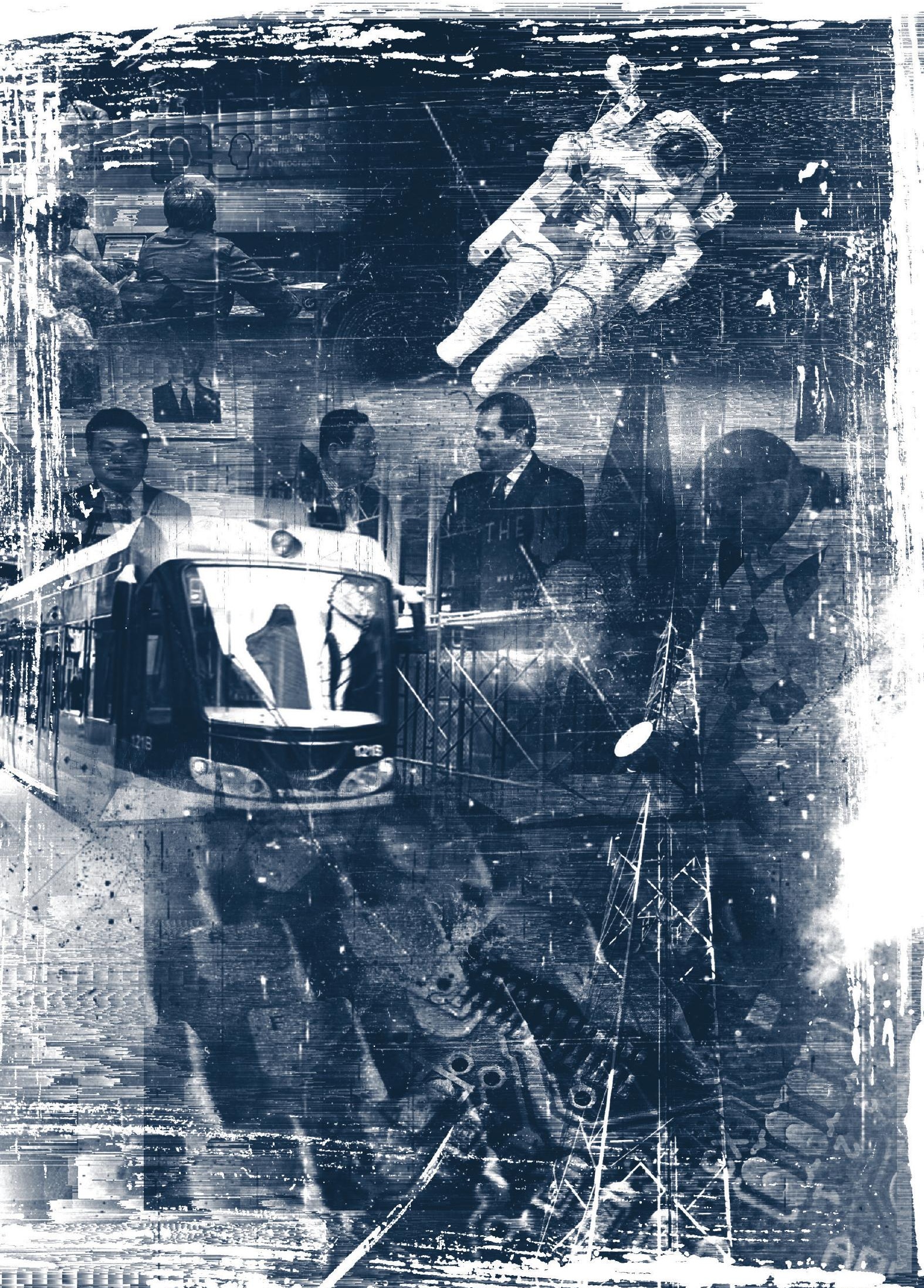




\section{A retórica da ilusão: Esboços da Cibernética no rastro da Sociedade da Informação}

The rhetoric of illusion: Cybernetics sketches in Information Society track

DOI: 10.15213/redes.n10.p327

RODRIGO SATURNINO

\section{ABSTRACT}

The article highlights relevant social phenomena behind the entry of the concept of information within the political and economic field. It aims to understand how this social process is articulate with the recent digitalization and commodification of information, as an attractive field of regulation subjected to privatization and commercial exploitation. The theoretical analysis drifts from the so-called first Cybernetic's project and from its derivations in Social Sciences.

KEYWORDS: CYBERNETICS, COMMUNICATION, SOCIAL SCIENCES, INFORMATION, INTERNET

\section{RESUMO}

O artigo destaca a importância de alguns fenômenos sociais que antecederam a entrada da informação no campo da disputa política e econômica. O objetivo é registrar como este processo preparou o terreno para a sua posterior digitalização e, consequentemente, para sua mercantilização, tornando-se num atraente campo de regulação submetido por lógicas de privatização e exploração comercial. O texto foi baseado no projeto da chamada Primeira Cibernética e os seus posteriores resíduos teóricos encontrados no rastro da produção científica das Ciências Sociais.

PALAVRAS-CHAVE: CIBERNÉTICA, CIÊNCIAS SOCIAIS, COMUNICAÇÃO, INFORMAÇÃO, INTERNET 


\section{INTRODUÇÃo}

Na literatura sobre o desenvolvimento das tecnologias da informação é comum nos depararmos com uma diversificada produção teórica orientada pela conjugação da gênesis do universo biológico e o funcionamento da maquinaria tecnológica. Estas associações, herdeiras de um gnosticismo do tipo tecnológico, tentam estabelecer projeções orgânicas entre o homem e a máquina para, desta forma, facilitar a sua penetração no tecido social como uma relação indispensável e, acima de tudo, legitimar a tecnociência como um meio de superação dos limites e da finitude da condição humana (MARTINS, 1993, p.230; 2011, p.18).

No campo da comunicação, as retóricas mecanicistas que buscaram simplificar a organicidade dos seres vivos através de paralelizações utilitárias em relação à tecnomaquinaria, voltaram a ser reiteradas, de modo constante, a partir do intenso desenvolvimento das Novas Tecnologias da Comunicação e Informação (NTCIs), sendo a sua maior incidência entre os anos de 1970 e 1990.

Considerando a criação da Internet como divisa fundamental deste regresso, a eloquência do discurso tecnocientífico contemporâneo substituiu o anterior elogio do sublime tecnológico (MARX, 2000) pelo louvor do eletrônico sublime (carey, 1989), fazendo da tecnologia uma hipérbole argumentativa e vital para a consecução de políticas econômicas, sociais e científicas. A sinergia foi defendida, por exemplo, por expressivos nomes do pensamento ocidental, sendo os mais populares: Negroponte (1995), Wellman (1999), Castells (2003; 2005; 2007), Toffler (1989) e Lévy (1997). Quando escreveu Being Digital, Negroponte (1995) chegou a considerar a era digital como uma força da natureza, um fenômeno veemente impelido pela ordem consequente da essência do ser humano enquanto indivíduo socialmente comunicativo. $O$ tom profético das previsões que fez em relação à digitalização da sociedade, integra o escopo das prognoses prometeicas fundacionais, para usar a expressão de Martins(2011) das versões correntes acerca do papel emancipatório e libertador do conhecimento científico e das NTCIs.

No rastro das perspectivas tecnológicas, o trabalho acadêmico de Castells figura como uma importante referência neste tipo de debate. Ao ponderar a Internet como o coração de um novo paradigma sociotécnico, defendeu que ela constituiria toda a base material das nossas formas de relações sociais, devido à sua potencial força de promover a organização, através do seu caráter reticular, da complexidade das relações sociais(CASTELLS, 2003, p. 287). $\mathrm{Na}$ visão do autor, no cyberspace - entendido como figura reticular da utopia 
tecnológica, no sentido atribuído por Musso (2006) - o jogo político e os conflitos sociais seriam melhor administrados devido ao caráter estrutural que a Internet, pensada pela metáfora da rede, proporciona às sociedades no sentido de permitirem a ordenação dos fluxos informacionais que circulam através das suas teias.

$\mathrm{Na}$ apreciação do autor, a Internet não cria um modelo de individualismo em rede. Ao contrário, ela proporciona o seu desenvolvimento ao providenciar o suporte material apropriado para a difusão do individualismo em rede como forma dominante de sociabilidade (CASTELLS, 2007, p.161) gerando o que Lévy (1997) considerou ser a origem de uma inteligência coletiva. Deste modo, a expansividade das experiências sociais mediadas pelas NTCIs, lembrando a obra de McLuhan (1965), convergiu na objetivação de uma nova sociedade alicerçada por uma espécie de corporização tecnológica capaz de amplificar a ontologia humana através do surgimento de um ser e um self digital. Neste sentido, as figuras de linguagem, e até mesmo as imagens fictícias do homem refeito de Allan Poe em The man that was used up, acerca de um ser informacional deixaram a sua condição fantasmagórica para tornar-se em uma condição empírica, recursiva e pragmática de todos os indivíduos (TURKLE, 2005; 2011).

Não obstante, é incontestável admitir os impactos e os efeitos sociais causados pelas inovações tecnológicas - nomeadamente no âmbito da comunicação - , nas diferentes áreas por elas influenciadas. No domínio econômico, apoiada pelo enquadramento da informação no campo do trabalho, as NTCIs serviram de stepping stone, para o usar o jargão informático, de ascensão fulminante de novas empresas e de novos modelos de produção. Na política, elas emergiram como fonte fidedigna para ações programáticas partidárias subsidiadas por ideologias concentradas nas suas potencialidades cívicas de integração mundializada. No espectro sociológico, as NTCIs passaram a ser interpretadas como recurso fundamental para o empowerment e no antropológico, determinaram uma nova existência cultural para o Homem. Vale destacar que o quadro de transformação social recebeu forte impulso através do intenso aprimoramento tecnológico de sistemas capazes de suportar grandes volumes de trocas de dados informáticos e, também, por meio da rápida evolução no fabrico de artefatos tecnológicos mais velozes, mais acessíveis e mais amigáveis, tornando o processo de domesticação das tecnologias - menos oneroso no âmbito cognitivo e em relação aos preços praticados no mercado.

Ao lado das inovações na indústria da informática, o investimento irrestrito em pesquisas científicas no setor das tecnologias de comunicação corroborou para que a noção de "informação" ocupasse um lugar proeminente 
como partícula vital de todos os processos interativos, mediados pelas máquinas ou não. Neste sentido, a ideia de informação - seguindo o seu rastro histórico a partir dos primeiros usos do conceito nos trabalhos de Shannon, Weaver e Wiener - passou a ser admitida, também, como um instrumento estrutural do poder (BRAMAN, 1989, p.241).

$\mathrm{Na}$ cadeia produtiva do conhecimento científico, a elevação da informação como objeto quantificável a partir das categorias, por exemplo, da engenharia matemática da Cibernética, representou importante condição que deu azo à formação de um novo projeto social e econômico - recortado por um caráter utópico - de reconstrução do mundo em todos os seus aspectos. A afirmação da informação e a valorização pragmática de um novo sistema de valores sobre o tema da comunicação, ressoa como pano de fundo que hoje sustenta uma nova política para a vida humana. No espectro internacional, as manobras neoliberais de desregulamentação do mercado das telecomunicações dos Estados Unidos em meados dos anos de 1950 figuraram como parte fundamental da história política e econômica da informação (schILLER, 2000). O programa partidário levado a cabo pelo governo de Bill Clinton através do seu vice-presidente Al Gore no início de 1990, expressa um importante marco no processo de legitimação social do consumo de informação e do uso das novas tecnologias como recurso essencial para o desenvolvimento econômico mundial. O termo information superhighway, outrora designado enfaticamente pelo mandato do democrata como expressão revolucionária da atividade social, foi abandonado, servindo apenas como sinônimo das políticas de liberalização do mercado telemático (FLICHY, 2008).

O universo imaterial explorado pelas indústrias baseadas no digital adquiriu robustez empírica e está representado pelo grande volume de capital gerado através das fusões corporativas que dominaram integralmente este setor, constituindo a elite matemática da indústria eletrônica baseada na álgebra booleana. $\mathrm{O}$ poderio institucional foi suficiente para permiti-las enfrentar, insolentemente, o estouro da bolha da Internet em 2001 e a crise financeira mundial de 2008 através de extraordinárias manobras concorrenciais de sustentabilidade (sCHILLER, 2007). Na altura, a Cisco acumulou rendimentos que atingiram 20 bilhões de dólares no início de 2009. A Apple, US\$ 26 bilhões; A Microsoft, US $\$ 19$ bilhões; A Google, US $\$ 16$ bilhões; a Intel, US $\$ 10$ bilhões e a Dell, US $\$ 6$ bilhões.

Apesar da prosperidade ávida das gigantes do setor durante a passada crise financeira mundial não ter atingido em massa o mercado da informática, a criatividade das empresas de tecnologia da informação demonstrou a sua força de recomposição econômica nos anos posteriores. Empresas do 
ramo da telefonia móvel como a Motorola e a Sony Ericsson em 2010 reverteram suas perdas em lucros suficientes para mantê-las entre as mais rentáveis do mercado mundial. O mais recente prodígio deste ramo de negócios é o nicho das redes sociais virtuais. Das centenas existentes, o Facebook é a mais lucrativa, avaliada em cerca de 170 bilhões de dólares, como estimativas de mil milhões de utilizadores em todo o mundo.

Ora, ao admitirmos que o êxito destas empresas se integra ao quadro histórico e contínuo dos processos de legitimação social das NTCIs, o propósito deste texto é lançar o olhar sobre a perspectiva que advoga o surgimento da Cibernética como um dos marcos históricos da legitimação da comunicação enquanto processo inerente à formação integral das sociedades, tendo como ponto de partida as contribuições de Wiener e o trabalho de Shannon e Weaver. O texto faz uma breve incursão sobre as principais teses acerca da informação e explora alguns de seus traços utópicos a partir da contraposição realizada por teóricos como, por exemplo, Breton (1992;1997; 1995), Schiller (1988, 2000; 2007) e Mattelart (1991; 1996; 1999; 2000; 2002). Em resumo, o trabalho destaca a importância de alguns fenômenos sociais - influenciados por uma forte dependência das ideologias majoritárias do pensamento ocidental - que antecederam à entrada da informação no campo da disputa social, política e econômica ao refletir sobre o reconhecimento da comunicação como "paradigma dominante" contemporâneo. Interessa registrar como estes processos prepararam o terreno para a posterior digitalização da informação e, consequentemente, para sua mercantilização, tornando-se num atraente campo de regulação submetido por lógicas de privatização e exploração comercial.

O texto não converge para uma análise tecnofílica, muito menos concentra-se em manter um discurso tecnofóbico a respeito da função da tecnologia enquanto artefato social. Também não se aproxima do purismo humanista que busca afirmar distanciamentos e binarismos conceituais para, desta forma, desqualificar o papel da tecnologia na transformação da sociedade, nem afirma a sua fatalidade filosófica como instrumento de enfraquecimento dos laços sociais. O texto elabora um registro qualitativo, de modo recortado e descritivo do percurso que cobre o início da Cibernética até a elaboração conceitual da chamada Sociedade da Informação e as suas variadas dobras ideológicas: sociedade do conhecimento, sociedade informacional, era da informação, sociedade da comunicação, entre outras.

É importante acentuar que a viragem científica proporcionada pela Cibernética, apesar de ter sido silenciada nos corredores acadêmicos, continua, residualmente, presente no rastro ideológico Sociedade da 
Informação"(CONWAY; SIEGELMAN, 2005; LAFONTAINE, 2004; PFOHL, 2001). Naturalmente, os anos de ouro dos debates travados durante as Conferências Macy foram esquecidos por grande parte da teoria social contemporânea. Da mesma forma, a euforia científica baseada nas descobertas de Wiener que vigorou tanto nos Estados Unidos, e mais tarde, na União Soviética e nos projetos de Allende no Chile de 1971, foi completamente banida do cenário mundial ${ }^{1}$.

No campo das Ciências Sociais, o que restou da Cibernética parece ser fruto de uma amnésia convencional. $\mathrm{O}$ aparente desconhecimento sobre a dinâmica das inúmeras técnicas de tratamentos de dados e a apatia histórica em relação aos contextos que a antecedem, reforçam uma recorrência amorfa que caracteriza a produção acadêmica nas áreas afins à sociologia, à antropologia, à psicologia social, à ciência política e à comunicação. Esta "perda" da memória científica conduziu o legado de Wiener ao que poderia ser chamado de "pódio da misericórdia". No senso comum da academia, a Cibernética é apenas um prefixo-mãe, um recurso linguístico utilizado para mimetizar novos vocábulos tecnológicos. Mais importa dizer que, relembrando as palavras de Martins (2005), o campo inaugurado pela Cibernética no seio da comunidade científica é de tão longo alcance que negar a sua penetração e a consequente influência no nosso modo de entender, por exemplo, as formas de interação humana, seria por completo um ato de ingenuidade diletante. É lamentável confirmar o caráter inepto da pesquisa científica contemporânea que desconsidera a sua origem, como também é lastimável testificar as rasas associações intelectuais entre o conceito de comunicação, o "bem maior" da Cibernética, e a função exercida pelos chamados media. Há quem defenda que este desconhecimento manifesto revela, em entrelinhas, o quanto as nossas sociedades informatizadas tem de incorporado no seu cotidiano a essência da Cibernética. Não é o que se argumenta neste artigo. $\mathrm{O}$ texto não intenciona resgatar o mérito matemático da Cibernética, muito menos pretende reerguer a sua retórica apoteótica e maniqueísta como paradigma dominante. Ao contrário, ao considerar a perda do brio inicial da utopia de Wiener, o texto registra os vestígios remanescentes que permaneceram pulverizados na dinâmica produtiva das Ciências Sociais e nos desdobramentos políticos que a sucederam. Tais resquícios demonstram como o patrimônio wieneriano serviu de

1. Para uma visão geral da repercussão da Cibernética na União Soviética, ver Gerovitch (2002). No livro o autor descreve como os ciberneticistas soviéticos transformaram a proposta de Wiener em um movimento social interessado na mudança radical da ciência e da sociedade. 
base para cimentação de uma sociedade cada vez mais caracterizada por uma cibernética autocrata, arbitrariamente, transformada em uma tirania informática apoiada na fantasmagórica busca por uma sociedade homeostática.

A fim de delimitar nosso campo de verificação, o texto foi dividido em três partes. Na primeira, apresenta-se o projeto original da Cibernética, tendo como base as propostas de Norbert Wiener. Na segunda parte, destaca-se, em forma de um breve panorama, os resíduos encontrados em algumas formulações teóricas da produção científica das Ciências Sociais. Na parte final, a reflexão concentra-se em verificar as nuanças cibernéticas que fizeram parte da composição ideológica da "Sociedade da Informação" a fim de debater até que ponto a sua formulação figura como um resultado retórico - sem desconsiderar as evasividades que dela emergem -, favorável aos interesses privados, nomeadamente em relação ao conglomerados econômicos que se formaram a partir da mercantilização dos conteúdos digitais.

A par das variantes formas de interpretação acerca da informação, fica registrado que a intenção do presente artigo é tentar perseguir a sequência enunciada a fim de traçar um quadro anatômico que dê conta papel estruturador que ela tem exercido desde as premissas de Wiener. Seguindo este raciocínio, será possível destacar a importância de alguns fenômenos sociais que contribuíram para a sua entrada no campo das disputas políticas e econômicas.

\section{ANTES DA INFORMAÇÃO, A UTOPIA}

A primeira referência cronológica acerca da palavra "utopia" é comumente associada à obra homônima de Thomas More (1997). Ela serve-nos aqui não para esmiuçar a sua complexidade conceitual, mas apenas para exemplificar, em forma de súmula, o debate que persegue, ainda hoje, a elaboração do pensamento ocidental, seguido da sua justificação e da sua legitimação enquanto representante simbólico da ruptura com os fundamentos tradicionais a que estava submetido a sociedade europeia desde o século xIV.

A obra de More, longe de ser nosso inequívoco exemplo de revolução social, ainda representa um traço recorrente e duradouro na ideologia da cultura do Ocidente. Os que consideravam a antevisão de More uma proposta idealizada de um Estado harmonioso, acreditavam que a elaboração de formas próprias de compreensão e de superação dos infortúnios sócio-políticos dos períodos totalitários, era fruto das crises enfrentadas pela sociedade medieval. More escolheu idealizar uma sociedade homeostática através do contraste com a Inglaterra em que vivia. Para os que preferiam interpretá-lo do ponto de vista da sátira, Utopia figurava como uma alegoria humanista da 
impossibilidade da ciência e da política em trazer à realidade o desejo do autor. A primeira visão tornou-se a mais socializada. Ao contrário dos sátiros, o otimismo científico elevou-se para destituir a doxa e o dogma através da constituição de um corpo filosófico-analítico, próprio e autônomo - e aqui sim, ironicamente, utópico - suficientemente forte para emancipar e devolver aos seres humanos a sua autonomia.

Segundo o imaginário que emergiu desta nova construção filosófica chamada "ciência", os mistérios metafísicos enfrentados durante a revolução científica dos séculos XVI e XVII só foram suplantados depois da invenção de outro corpo enigmático, ou seja, através da métrica metodológica de todos os fenômenos ${ }^{2}$. A figura do "cientista" foi elevada como o novo sacerdote - em substituição aos ministros teológicos - de um postulado repaginado pela insistente necessidade empírica da prova que conduziria o homem à sua maioridade social. $\mathrm{Na}$ sua ciência litúrgica, o especialista deveria dominar o pensamento abstrato, simbólico e imaginário - muito comumente associado ao pensamento teológico do período pré-iluminista - através da criação de outro pensamento, nomeadamente o científico. Para além de simplificar a complexidade da natureza humana, o esforço do cientista se resumia em garantir ambientes homoestáticos e resistentes ao caos e à contigente desorganização do mundo. Esta condição não indicava, necessariamente, uma consequência direta do incumprimento das promessas retóricas do Iluminismo. Ao contrário, apenas sinalizava o desejo de suplantar a especulação filosófica e, assim, devolver ao indivíduo a capacidade de entender e prolongar a sua própria ontologia. Parafraseando Descartes (1980), através do analítico o homem deveria tornar-se não mais senhor dos mistérios jocosos da filosofia especulativa, mas dominador e possuidor da natureza em todas as suas formas.

O idealismo em torno do papel da ciência - justificada pela ideia da evolução do Homo Sapiens (tanto através do processo de sua ereção biológica, como do exercício do Cogito ergo sum) e pelo progresso das elaborações de técnicas "muito úteis à vida", segundo Descartes (1980) - encontrou lugar à luz, por exemplo, da obrigatoriedade escolar e do surgimento de veículos de comunicação, como a Imprensa. A utilização intensiva não só dos livros, mas de todo um arcabouço utilitário dos meios de comu-

2. Não desconsideramos o caráter científico que se encontra nas investigações empíricas dos períodos greco-romano e medievais. Optamos por utilizar como referência o que atualmente, se convencionou chamar de "ciência moderna" considerando seu início durante a retomada científica realizada pelos renascentistas. 
nicações como os jornais e os correios, revigorou a expansão do projeto emancipatório a todos os indivíduos através da democratização do conhecimento e da extinção da iliteracia.

A supervalorização de uma razão instrumentalizada pelo qual passou as sociedades pós-teológicas era sintomática. O escrutínio dos seus imbricamentos nada mais revela do que a dificuldade na qual a legitimidade da ciência estava submersa ao ser admitida como argumento político laureado por preeminências religiosas e por interesses semelhantes à empreitada levada a cabo pelo fazer teológico. A crença da ciência teria um fim exitoso na medida em que o seu modelo analítico do conhecimento racional fosse transferido para todo o escopo da organização social (HABERMAS, 2009, p. 74). A que tudo indicava, nas sociedades sem tutela religiosa a aquisição de um conhecimento formalizado ou "a repetição complacente de 'verdades' triviais e vazias", para usar a expressão de Hannah Arendt (2001), figurava como principal indicador da transição social pela qual passou o homem medieval (MATtelart, 1996; arendt, 2001). Sob a égide do conhecimento formalizado, o projeto de organização social do Iluminismo se estabeleceu, elevando-se como alternativa indissociável ao mito da emancipação social.

O feito mais evidente deste processo foi a monolitização social pela qual passou a forma do pensamento humano, sendo, desde lá, admitido como recurso indelével para qualificar os indivíduos e o mundo no qual se encontravam, inevitavelmente, submersos. E assim, a ideia de emancipação permaneceu como trampolim filosófico, perseguida como partícula fundamental de períodos de crises de identidade social e a nada mais serviu, a não ser como estímulo para a elaboração de novas utopias e de todos os paradigmas que as sucederam. Vale ressaltar que a libertação do modo de pensar e a confiança no progresso científico sofreram fortes clivagens e intensos questionamentos depois de favorecer a instrumentalização militar no período da primeira grande guerra. As disputas políticas no âmbito mundial, o terror dos nazis e o sangue dos campos de batalha evidenciaram o fracasso da confiança humanista no protagonismo insolvente da ciência, da tecnologia e dos modelos econômicos, políticos e sociais que emergiram nas sombras da sua efervescência. Posteriormente, a crise do pós-primeira guerra estabeleceu duas fases: uma marcada por uma agudeza de discursos concentrados em rebater os pressupostos do otimismo tecnocientífico, e outra decidida em renovar o paradigma científico através da formulação de novas premissas. Os fenômenos da linguagem e da comunicação foram sustentados como um dos principais paradigmas 
emergentes nestes períodos. A premissa era básica: a comunicação deveria ser exaltada como única fonte de harmonização dos mundos social, biológico e maquínicos.

\section{O SONHO DE WIENER: A PRIMEIRA CIBERnÉtiCA E SEU CARÁter SOCIO- LógICo}

No campo empírico, a Cibernética emergiu como principal projeto a articular, através do paradigma comunicacional, o caminho de volta à sociedade ideal. No rascunho deste esboço científico, a emergência de uma teoria da informação - progenitora do Homo Communicans - recebeu importantes contributos a partir do trabalho de cientistas interessados na unificação de práticas sociais e na sua legitimação do ponto de vista estruturalista. O maior trunfo desta incursão foi o de estabelecer um aparato filosófico consistente e o de incluir a informação na categoria de objeto quantificável através da transferência e da transposição de modelos de cientificidade próprios das ciências exatas (MATTELART, 1999; BRETON, 1992; SCHILLER, 1988)

A figura do matemático Norbert Wiener ainda é considerada a mais popular e a mais representativa da cadeia teórica da chamada primeira Cibernética (sfez, 1993, p. 743). A associação direta como "pai da Cibernética moderna" foi atribuída devido a dedicação prestada na elaboração de um método capaz de descrever e medir a qualidade e a quantidade das trocas de informação a partir de alguns experimentos eletrônicos (CONWAY; SIEGELMAN, 2005). O livro Cybernetics or control and communication in the animal and the machine, publicado em 1948, foi aclamado como a obra fundacional, do ponto de vista técnico, desta "nova ciência".

A noção de informação constitui o núcleo duro da Cibernética. Apesar do esforço analítico dos variados cientistas que propuseram uma definição conceitual, não há instabilidade descritiva acerca da sua constituição devido ao seu caráter multifacetado e polissêmico, conforme salientaram Furtado (2012) e Floridi (2010). O que se tem convencionado fazer, nos estudos que a envolvem, é delimitá-la a partir da ciência que dela se refere, admitindo que todo conceito é uma construção planejada e que nem sempre ele, enquanto instrumento discursivo, é fruto de um consenso monopolista (CAPURRO; HJøRLAND, 2003). Aliás, como qualquer outro conceito, a variação serve menos para afirmar suas características morais (positiva, negativa ou neutra) e mais para localizar aquilo que se trata em relação ao desempenho do seu papel numa ação prática. Neste sentido, admitir a transdisciplinaridade e a interdisciplinaridade da informação adianta sua capacidade epistemológica de cir- 
cular por diferentes teorias e por outro lado, a sua flexibilidade de aplicação segundo, se for o caso, parâmetros situacionais persuasivos que convirjam para interesses específicos (BRAMAN, 1989). Ademais, a teleologia da informação recupera o debate filosófico, presente no trabalho precursor de Ellul (1980), acerca das tensões ideológicas entre as abordagens objetivas e as subjetivas, principalmente devido ao seu caráter versátil, heterogêneo e plural. Desta forma, a noção de informação figura como uma conjugação movediça e um construto teórico, operacional e polarizado pelas opções políticas sobre o seu significado. Na acepção de Weaver (1949) qualquer análise da informação deveria ser realizada a partir de uma interpretação tripartida considerando os problemas técnicos com a sua quantificação, os problemas semânticos relativos ao significado e à verdade e os problemas que influenciam o seu impacto no comportamento humano (WEAVER, 1949; FLORIDI, 2008, p.06). De modo geral, as abordagens qualificativas da informação resumem-se a partir de três grandes campos: o sócio-discursivo (pragmático), o técnico-operacional (matemático) e o cognitivo (semântico) (WEAVER, 1949).

Wiener defendeu a ideia de informação como um termo para designar o conteúdo daquilo que permutamos com o mundo exterior ao ajustar-nos a ele e que faz com que nosso ajustamento seja nele percebido. Para Wiener, o "processo de receber e utilizar a informação é o processo de nosso ajuste às contingências do meio ambiente e de nosso efetivo viver nesse ambiente" (WIENER, 1978, p.17-18). Um exemplo comumente associado a este fenômeno pode ser estabelecido através do termóstato, um instrumento que consegue controlar a temperatura ambiente a partir da informação que recebe do exterior. Seu sistema de autocontrole evidencia a capacidade tecnológica deste dispositivo em orientar-se a partir da interpretação correta que faz da temperatura a fim de manter o ambiente climatizado. O equilíbrio em que opera o termóstato dá-se pela aplicação das regras da Cibernética. Ou seja, sua orientação realiza-se devidamente porque seu interior está dotado de uma capacidade de autocontrole. Este princípio, para a teoria da Cibernética, pode ser tomado como uma evidência importante no controle da informação, tornando-se o ponto de partida para o equilíbrio técnico e social. No campo epistêmico, a informação chegou a ser considerada como uma superação da antiga convergência do pensamento científico acerca da categoria "energia". A súbita alteração proporcionada pela primeira Cibernética, ao trocar os watts pelos bits, renovou todo o arcabouço dos métodos analíticos e transformou, profundamente, o quadro geral das análises sociais.

$\mathrm{O}$ equipamento retórico de Wiener sustentava o mundo como um organismo regido pelo processo de permuta recursiva da informação. Neste uni- 
verso, a realidade de qualquer relação (natural e artificial) só poderia ser interpretada, integralmente, através da mediação dos processos informacionais, ou seja através da comunicação. Wiener (1978) acreditava que a sociedade seria, finalmente, homoestática e autopoiética se os homens compreendessem a função e a importância dos processos comunicacionais que integram a totalidade da existência do mundo.

De modo geral, o principal pressuposto de Wiener foi afirmado baseando-se nas formulações de Leibniz acerca da automatização do raciocínio e da criação de uma linguagem universal. Na esteira de fisiólogos como Ivan Pavlov, Andrey Kolmogorovo e John Von Neumann, o contexto do trabalho do matemático ficou marcado pelo esforço realizado durante a II Guerra Mundial, época em que estava envolvido com pesquisas relacionadas aos mecanismos de controle da artilharia antiaérea e a programação das primeiras máquinas computadoras.

Neste período, Wiener concentrava as observações no sistema de lançamento de projéteis e as suas respectivas trajetórias. Considerando o dispositivo eletro-mecânico do sistema, Wiener utilizava um princípio da engenharia de controle, que ele passou a denominar de feedback, para sustentar a ideia da retroalimentação de informação. Desta forma, garantiria que a rota do projétil fosse, de fato, bem sucedida. O sistema de retroalimentação previa uma compensação de possiveis desvios no desempenho do mecanismo de forma a corrigir erros futuros. Para Wiener (1948), o bom funcionamento de um sistema dependia da sua habilidade sensorial em diferenciar mensagens certas das equivocadas. $\mathrm{Ou}$ seja, ao enviar um comando $\mathrm{x}$ para uma máquina à espera de um desempenho y, caso a máquina executasse uma ação não correspondente, ficaria sinalizado que o seu sistema de retroalimentação necessitava de informações que permitisse à máquina compensar qualquer desvio cometido durante o processo de realização do pedido. O sistema de retroalimentação funcionava como um detector capaz de diferenciar as ações solicitadas a um agente. $O$ desempenho realizado pela máquina só seria compensado de modo a se tornar o esperado a partir da informação que o sistema de retroalimentação enviasse a fim de aproximá-lo de um "comportamento" padronizado. Se um dispositivo não contivesse a informação suficiente para discernir as diferenças entre A e B, dificilmente o desempenho realizado se consumaria no esperado.

Em parceria com o fisiologista Arturo Rosenblueth e o engenheiro Julian Bigelow, Wiener notou que este método de controle apresentava oscilações crescentes colocando em risco a estabilidade e o equilíbrio do sistema. Nos testes em seres humanos, observou uma correlação entre pacientes com problemas de ataxia. A dismetria, ou a perda da coordenação motora e os movimentos descoordenados realizados por músculos saudáveis, segundo Wiener, surgia 
da insuficiência de informações no feedback que o sistema cinestésico destes pacientes emitia para o sistema nervoso. Segundo suas apreciações, o sistema sensorial humano funcionava de modo cíclico, dependente das informações (ou das mensagens) que enviava aos músculos e das que retornavam pelos órgãos dos sentidos - um princípio que Wiener considerou como similar aos dispositivos de controle das máquinas (WIENER, 1948, p.15; WIENER; ROSENBLUETH; BIGELOW, 1943).

As experiências do matemático foram precursoras no campo da chamada "inteligência artificial". Seu principal interesse era, através da prova empírica, estabelecer uma associação direta entre a dinâmica do funcionamento das máquinas e a organização social para, daí, dar força ao antigo desejo iluminista de tornar possível a harmonia entre humanos, máquinas e animais. O caminho que escolheu partiu das analogias criadas entre o sistema nervoso central do ser humano e os dispositivos de controle das máquinas (WIENER, 1948, p.15; 1943). Este emparelhamento ampliou a teoria da transmissão da engenharia elétrica e envolveu um campo mais alargado, incluindo "não apenas o estudo da linguagem mas também o estudo das mensagens como meios de dirigir a maquinaria e a sociedade, o desenvolvimento de máquinas computadoras e outros autômatos" e assim, formalizar "uma nova teoria conjetural do método científico" (WIENER, 1978, p.15).

Os estudos de Wiener e Rosenblueth foram publicados no artigo Behavior, Purpose and Teleology e apresentados em 1942 à pesquisadores da Josiah Macy Foundation. A conferência foi o pontapé inicial que deu vazão à conhecida série de encontros interdisciplinares patrocinada pela mesma fundação, reunindo nomes populares da antropologia, da medicina, da biologia, da filosofia, da sociologia e da psicologia. Figuras como Gregory Bateson, Margaret Mead, John von Neumann, Claude Shannon, Talcott Parsons e Paul Lazarsfeld foram personalidades ativas durante os encontros realizados entre os anos de $1946 \mathrm{e}$ 1953 (HEIMS, 1991; LAFONTAINE, 2004).

No escopo da teria da Cibernética, o controle era a chave mestra. Na linguagem cibernética, controlar não indicava dominar nem reprimir, mas, basicamente, regular e comandar todas ações dos processos comunicacionais naturais ou artificiais. Em linhas gerais, o esforço das teorias e das experiências pretendia desenvolver um método consistente para conduzir os indivíduos à resolução do problema da comunicação em geral através de uma perspectiva que priorizava o estudo das mensagens, no sentido mais restrito, como forma de dirigir tantos as máquinas como as sociedades (WIENER 1978, p.17).

Apesar do nascimento da Cibernética enquanto ciência estar associado diretamente aos trabalhos desenvolvidos por Wiener e a outros cientistas que par- 
tilhavam da mesma teoria, o uso do termo é anterior à utilização feita no livro

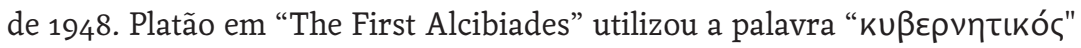
ou (kybernetikos) para fazer referência à capacidade de controle que deveria demonstrar um piloto de embarcações a fim de garantir segurança à tripulação, referência não esquecida por Wiener. Na França, na década de 1830, o físico André-Marie Ampère também fez menção à "Cybernétique" para descrever o futuro da ciência da governabilidade, relembrando a utilização do termo pelos gregos. Na Inglaterra, o físico James Clerk Maxwell também se referiu à terminologia como forma de nomear os seus estudos sobre mecanismos de repetição.

Sem desconsiderar o arcabouço histórico em torno da palavra "Cibernética", Wiener decidiu utilizá-la para descrever, levando em conta a ideia grega de "steersman" ou "piloto", “(...) the entire field of control and communication theory, whether in the machine or in the animal"(wIENER, 1948, p. 11). É interessante não deixar escapar que o pensamento da Cibernética seguiu, como esclareceu Martins (2011), o princípio elaborado pelo francês Claude Bernard no livro Introduction à l'étude de la medicine experimentale de 1865 . Nesta obra, o autor descreveu que o "isolamento do meio exterior, ou 'macrocósmico', e a estabilidade relativa do 'meio interno', ou 'microcósmico", depois denominado pelo fisiólogo W. B. Cannon a 'homeostase", (...) era uma "propriedade tanto dos seres vivos como das máquinas". A especulação de Bernard, escreveu Martins (2011, p.99),
[...] já abrangia as máquinas na sua formulação original
[...], modelizando e construindo máquinas cada vez mais
"organísmicas" neste sentido, elaborando modos de
comportamento maquinal orientado para fins, a correcção de erros, a aprendizagem, especialmente por "tentativas" e "erros", etc.

Na fase um pouco mais avançada, a Cibernética propunha que, assim como na condição autômata do ser humano em auto-regular a informação, as máquinas deveriam ser criadas respeitando uma condição, no mínimo, semelhante a este complexo sistema. Desta forma, estariam aptas para garantir sua autonomização enquanto steersman delas mesmas. Os resultados científicos relatados no livro de 1948 foram desdobrados para o público leigo na obra The Human use of Human Beings: Cybernetics and Society. Na publicação, a retórica wieneriana concentrou-se em divulgar a fórmula que sustentava todo o processo comunicacional. Wiener tencionava alargar o círculo de leitores através da tradução 
do caráter hermético da sua teoria matemática em um valor social facilmente apreendido por diferentes tipos de pessoas (WIENER, 1961; BRETON, 1992, p.29).

O projeto da Cibernética e as contribuições de Shannon e Weaver na década de 1940 foram cruciais para tais transformações. A equiparação da informação como objeto matemático, anteriormente entendida como elemento pertencente ao mundo das comunicações humanas, proporcionou uma forte convergência na sua anterior ontologia. Esta confluência foi intensificada através do movimento chamado de segunda Cibernética apoiada através das contribuições de Heinz von Foerster (SILVA, 2007). O novo quadro de pensamento proporcionou uma expansão do conceito, consolidando-se como programa científico de diferentes áreas da pesquisa. O campo da biologia recebeu forte influência, tonando-se um dos maiores êxitos da sua utilização através dos trabalhos de autores como Maturana e Varela (1995).

Para Wiener, o futuro proporcionado pelas contribuições da Cibernética dependeria de um compromisso social em garantir a harmonia das trocas interacionais no interior das sociedades. A retórica da Cibernética foi forte suficiente para unificar diversas disciplinas em redor do controle da informação como pressuposto último de combate à desordem social. A estratégia da Cibernética era consolidar uma cosmovisão organizada em redor do eixo do paradigma comunicacional a fim de envolver todos os processos sociais, ficando "latente a transformação da comunicação em 'valor' de amplo alcance social e político" (BRETON, 1992, p.23). Em outras palavras, a transversalidade e o caráter enciclopédico do mundo de Wiener era regido pelo processo de permuta circular da informação onde a realidade de qualquer relação (natural e artificial) só poderia ser interpretada, integralmente, através de sua mediação.

A acentuação desta premissa filosófica estabeleceu um marco na ideia da Cibernética como articuladora da constatação prática e teórica do processo comunicacional, expandido-se até envolver todos os campos científico-sociais. Sua concepção enquanto razão "ordenadora" da sociedade levada a cabo na obra de 1950, tornou-se a ponta de lança para o estabelecimento de um projeto utópico que, posteriormente, colaboraria para legitimar a comunicação como sistema aberto, servindo de eixo principal da ideologia que sustentava a homeostase social através do controle do seu processo. Segundo Breton(1992), o pensamento wieneriano desenvolveu-se com base em três ambiciosos objetivos: 1) criar caminhos para uma sociedade ideal; 2) estabelecer uma outra definição antropológica do homem e 3) promover a comunicação como valor (BRETON, 1992, p.46).

Wiener acreditava existir uma relação indiferenciada entre máquinas, animais e humanos. A convergência entre os três grupos refletia-se pela condi- 
ção comum no processo de partilha de mensagens - na maioria dos casos de modo dinâmico, aleatório, desorganizado e complexo - que ocorria no interior de cada um. A meta do matemático, portanto, era harmonizar - através do estudo das mensagens e das facilidades de transmissão que lhe são próprias - o caráter instável e neguentrópico destas partilhas a fim de garantir uma completa homogeneização da entropia (WIENER, 1978, p.16; BRETON, 1992, p.33)3.

Antes de levar a cabo este objetivo, Wiener ocupou-se em resumir toda a composição social a partir de duas etapas: 1) reconhecendo a constituição de uma sociedade a partir da sua natureza comunicacional (o ser-informação) e 2) identificando a natureza exata dos modelos de comunicação que uma determinada sociedade utiliza (o ser-intérprete). Em outras palavras, ao admitir que os sistemas mecânico, biológico e elétrico são formados a partir das trocas comunicacionais que realizam, Wiener encontrou lugar de destaque quando reduziu todos os fenômenos que se realizam no interior destes sistemas a partir do estudo daquilo que lhes era comum, ou seja a informação e as facilidades de sua transmissão. A este propósito, Fez (1993) salientou a mudança paradigmática realizada por Wiener ao transformar, progressivamente, a noção inicial dos comportamentos de trocas de informações pela ideia de "comunicação". Depois de Wiener, a ideia de comunicação não é admitida apenas como a simples troca de mensagens entre um receptor e um transmissor, mas como um modo de existência de todos fenômenos que existem entre eles (SFEz 1993, p.743). Wiener desenvolve, assim, uma forte proposição epistemológica em que a realidade social poderia ser explicada a partir das noções de "informação" e "comunicação. Desse modo, favoreceu não o desenvolvimento de uma nova disciplina científica [ou metodologia, conforme defendeu Stanley (1978, p.138)] científica, mas a oportunidade de renovar todo o arcabouço analítico e filosófico das ciências.

Para além do caráter técnico proporcionado pelos experimentos de Wiener, a promessa de um novo mundo dependeria de um compromisso

3. Neste sentido, a invenção do computador, tendo como pano de fundo a influência dos trabalhos de Turing (1950), figura como um marco histórico para a consolidação da Cibernética enquanto ciência empírica. Devido à sua natureza, a "máquina universal” tornou-se em (...) "máquina' de comunicar" e, de certa maneira, transformou-se na base de todo o dispositivo técnico de comunicação por ser dotada de um sistema binário capaz de neutralizar o processo entrópico da informação através da analogia wieneriana entre o seu funcionamento e o do indivíduo vivo (MATTELART, 2006; BRETON, 1992, p.34; WIENER, 1978, p.26). 
social em garantir a harmonia das comunicações no interior das sociedades. No seu entendimento, os avanços tecnológicos proporcionados pela descobertas cibernéticas deveriam ser resguardados por homens de bens que garantiriam a liberdade de expressão, a livre partilha e a livre circulação da informação e a constante utilização da comunicação como meio interativo. Afinal, segundo Wiener, tratava-se daquilo que nos concretizava enquanto seres humanos.

Apesar do seu aparente otimismo em relação às suas descobertas, o matemático guardava um temor: o de que a Cibernética fosse utilizada contrariamente ao seu propósito inicial e de que o novo tempo que seria inaugurado por ela levasse as pessoas a renderem a sua própria finalidade e todas as suas capacidades de escolha ao discurso sedutor da inteligência das máquinas. Este seria o prelúdio do fim da humanidade (Conway; SIEGELMAN, 2005, p.4). Wiener gastou os últimos anos de vida alertando políticos, empresários, sindicatos trabalhistas e o público em geral sobre as mudanças de longo alcance que ocorreriam no campo do trabalho e da vida diária. Como uma atalaia profética, Wiener foi uma das primeiras pessoas a alertar à comunidade científica sobre os perigos e as as tentações científicas que as máquinas inteligentes promoveriam no espectro das políticas tecnológicas. O avanço tecnocientífico que brotaria da Cibernética daria à humanidade não apenas a chance de evoluir em campos fundamentais para a vida humana, como a genética, mas também a responsabilidade moral de manter o poder produtivo da tecnologia resguardado da sua capacidade destrutiva.

O seu caráter utilitarista, sem dúvida, serviu como fonte de inspiração para as indústrias bélicas dos Estados Unidos e da União Soviética. E muito colaborou para a construção de bombas nucleares e de importantes teorias no âmbito das Ciências Sociais. Basta examinar a produção científica do variado grupo que integrou as conferências da Macy Foundation, para encontrar as evidências residuais da sua aplicação. Desta forma, a informação como paradigma emergente passou a fazer parte das visões objetivistas e subjetivistas, tornando-se em uma categoria, abundantemente, híbrida. Do mesmo modo, como defendeu Breton (1992) e Lafontaine (2004), a ênfase no conceito de "sociedade de comunicação", representada pelo projeto ciberneticista, emergiu como uma resposta à crise das ideologias políticas que antecederam tais experiências científicas. O caráter "anárquico" da Cibernética de Wiener permitiu tanto uma visão mecanicista do mundo, como também autorizou uma concepção orgânica da vida. E a grande descoberta, quiçá o maior trunfo da proposta wiene- 
riana concentrava-se na afirmação e no ajuste da comunicação como uma ideologia, ontologicamente, integracionista e plural, pronta a suportar o fracasso das promessas tecnológicas dos anos predecessores às guerras mundiais através de uma conceitualização da natureza capaz de reintegrar conceitos díspares, ratificar valores e normas superiores e proclamar a diversidade e a unidade do mundo por meio da elaboração de uma ideia comum.

\section{RESÍdUOS CIBERNÉTICOS NAS CIÊNCIAS SOCIAIS}

Apesar de ter sido banido do cenário norte-americano dez anos após sua morte em 1960, algumas das profecias de Wiener foram, gradativamente, reconhecidas. Milhões de pessoas perderem os empregos em fábricas de automóveis depois da invenção de máquinas autocatalíticas e autômatas. As descobertas da biotecnologia de moléculas de neurotransmissores que percorrem caminhos irregulares através do cérebro e da corrente sanguínea, confirmaram os seus palpites acerca dos neuro-hormônios. $\mathrm{Na}$ área da micro-informática, a miniatuariazação dos computadores, dos microchips e as conjugações filosóficas entre meatware e software também fazem coro às previsões do matemático (MARTINS, 2011; CONWAY; SIEGELMAN, 2005, p.244-245). Para além disso, o exemplo mais fresco das contribuições de Wiener está estampado na emergência e na elevação da Internet como cadeia rizomática mais importante do processo comunicacional humano e maquínico.

O processo social posterior à morte do matemático, principalmente a partir dos anos de 1970, foi marcado por intensos impulsos no desenvolvimento tecnológico e na progressiva informacionalização de áreas centrais da nossa existência. A própria ontologia do humano passou a obedecer, quase que de modo hegemônico, a categoria de veículo de informação, prolongando sua caracterização anterior de ser informacional (MARTINs, 2011, p.119) ${ }^{4}$.

A teoria wieneriana acerca da comprovação empírica da presença da informação no interior dos mundos físico, biológico e maquínico, colaborou, incisivamente, com a reorientação dos ramos da Ciência e da Tecnologia. E não foi só utilizada neste contexto. A variedade produ-

4. Para além da mudança na antropologia do Homem, o processo de informacionalização atingiu outros sistemas sociais como o da economia (através da digitalização do capital) e da física (por meio da inclusão da informação como uma categoria equiprimordial ao lado da matéria e da energia).(SCHILLER, 200o; MARTINS, 2011, p.118-119). Sobre a física digital, entre outros, ver a teoria “It from Bit" de Wheeler (1990). 
tiva do grupo que integrou as conferências da Macy Foundation, evidencia como os princípios da Cibernética foram desenvolvidos e aplicados de modo interdisciplinar (VON FOERSTER, 1950; 1951; 1952; 1953; 1955; MARTINS, 2005; KIM, 2004).

Gregory Bateson, exponente da Antropologia Norte-Americana, recebeu forte influência do pensamento de Wiener ao considerar que o conceito de informação proposto pelo matemático e a teoria naturalista da entropia, se não eram idênticos, eram muito semelhantes. Para Lafontaine (2004), depois de Wiener, o antropólogo foi elevado como a mais importante personagem do ativismo cibernético (LAFONTAINE, 2004, p. 60).

Em analogia aos conceitos estruturais de Durkheim sobre a solidariedade mecânica e orgânica, Bateson utilizou a teoria cibernética para defender que as dinâmicas sociais realizavam-se por que a humanidade fazia parte de uma biosfera mutualmente casual. No seu interior, a vida organiza-se a partir de um complexo sistema de comunicação, sendo determinada por relações simétricas e complementares. Bateson nomeou este fenômeno interacional de "schismogenesis" (cismogênese): "um processo de diferenciação nas normas de comportamento individual resultante da interação cumulativa dos indivíduos" (BATESON, 2006, p.219). Ao considerar o princípio da entropia como sistema circular e contínuo em busca de equilíbrio entre a ordem e o caos, associou as relações sociais como um sistema comunicacional dotado de recursividade de interações caracterizada por circularidades, oscilações, limites dinâmicos e feedback e, por isso, em constante alterações (RAPPORT \& OVERING, 2000).

A cibernética holística de Bateson (2006), segundo Rapport e Overing (2000), influenciou o trabalho de diversos cientistas sociais, sendo possivel encontrar resíduos posteriores ao seu trabalho nos escritos de Lévi-Strauss (1963; 1969), Laing (1976), Rappaport (1968), Goffman (1972), Strathern (1990), Paine (1976), Harries-Jones (1991, 1995), Almond \& Powell Jr. (1966), Deustch (1963), Easton (1968), Buckley (1971).

A teoria de Laing (1976) sobre o "eu dividido", de acordo com Rapport e Overing (2000), deve muito às ideias de Bateson sobre a esquizofrenia com "duplo vínculo" comunicacional. Os trabalhos de Goffman (1972), a respeito da manutenção da estrutura social e da realidade através de um processo socialmente sancionado por meio de "situational encounters" e de um "situated activity system", possuíam uma ligação distinta com a Cibernética. Já Lévi-Strauss $(1969 ; 1963)$ teria adaptado sua análise antropológica dos mitos, das trocas econômicas e dos sistemas de parentesco levando em conta a questão cibernética do constante processo de combinação e recom- 
binação de unidades comunicacionais. Segundo o autor, seria inconcebível a formulação de uma teoria da informação sem que afirmasse o universo informativo como parte indispensável do mundo natural (Caballero,1999, p. 21).

No feminismo antropológico, Strathern (1990) utilizou a figura do cyborg a fim de ultrapassar o modelo matemático de ordenação das coisas ao defender que a relação com a natureza das coisas realizava-se como efeito provocado pela relação recursiva e recíproca entre as partes em um determinado ponto no tempo e no espaço. Paine (1976) também juntou-se para fazer coro ao explorar como os circuitos comunicacionais podiam ser geridos estrategicamente de modo a se tornarem recursos políticos. Para Paine (1976), sendo a comunicação uma forma de envolver as mensagens em diferentes níveis de lógica de interpretações e decodificações, a natureza factual dos "mundos humanos" seria entrelaçada por questões de mediação, avaliação, retórica e poder. Desta forma, tornaria-se impossível uma diferenciação entre a informação pura e a comunicação socialmente inteligível, fazendo da "verdade" uma mera questão de convicção.

A lista continua. A partir das investigações na Nova Guiné sobre os ciclos periódicos da guerra ritualizada e a paz entre os Tsembaga, Rappaport (1968) considerou que a cultura só poderia ser entendida como um todo se fosse considerada como um sistema cibernético capaz de regular as relações entre as pessoas e o ambiente em que viviam. Harries-Jones (1991;1995) retomou ao conceito de Bateson (2006) para reforçar que a saída do "cisma ecológico" que o mundo tende a seguir, se daria apenas por meio de uma visão recursiva da vida, de modo a garantir a sobrevivência da espécie humana. $\mathrm{Na}$ Ciência Política e na Sociologia, os esquissos cibernéticos podem ser encontrados nos trabalhos de Almond \& Powell Jr (1966), Deutsch (1966), Easton (1968) e Buckley (1971). Enquanto os três primeiros, defendiam o uso da Cibernética de modo "filtrado" no processo de abordagem do estudo da política sobre o ponto de vista dos sistemas comunicacionais que a constituem, na sua "moderna teoria dos sistemas", Buckley (1971) clarificou sua íntima conexão com a disciplina, justificando sua escolha pela ligação que estabeleceu entre os termos cibernéticos e a pesquisa geral do sistemas que elaborou. Do mesmo modo, Easton (1968) expôs na sua teoria da análise política a relação social do Estado e dos cidadãos através de entradas nominativas (inputs e outputs) resgatadas do campo da Cibernética. O envio de inputs, para este autor, era uma forma de manter o diagrama do sistema político persistente e em rotatividade. Neste processo, o sistema político permitiria o envio de inputs pela sociedade a fim de proporcionar ao Estado uma forma de verificar a reação social a partir dos seus outputs emitidos. Easton, curiosamente, 
considerava este processo como o feedback do processo de funcionamento do sistema. Seguindo o raciocínio winneriano em relação às máquinas, Easton acreditava que quanto mais o Estado recebesse pressões sociais(inputs), mais ele poderia gerar outputs e, consequentemente, examinar como procediam os intervenientes diante das suas decisões, mantendo o sistema circular e persistente, ou seja, controlado.

Lafontaine (2004) defendeu que a penetração da Cibernética nas Ciências Sociais ficou evidenciada muito mais do ponto de vista ideológico do que, exatamente, em relação às questões do progresso técnico. $\mathrm{O}$ tema da comunicação seria o ponto de interseção entre as Ciências "Naturais" e as "Sociais", tornando-se a problemática comum entre ambas devido à sua natureza heterodimensional (CABALLERo, 1999). Além do mais, esta estratégia, segundo a interpretação oferecida pela autora, fazia parte do interesse institucional dos teóricos envolvidos com as premissas cibernéticas. No contexto posterior à Segunda Guerra Mundial, os especialistas das Ciências Humanas passaram a gozar de um elevado prestígio social e a receber muitos incentivos para a pesquisa, depois de serem mobilizados pelo governo para fins de propaganda e investigação.

O caso de Margaret Mead ilustra como o projeto da Cibernética era utilizado nos estudos que realizou sobre a saúde mental. De forma a contrariar a influência crescente do marxismo, os estudos da World Federation for Mental Health privilegiavam uma visão estrutural do mundo, defendendo programas políticos elaborados a partir de uma lógica baseada na engenharia social. As hipóteses de Mead colaboraram para construir um plano filosófico acerca dos problemas sociais. Para Mead, as raízes dos conflitos sociais constituem respostas estimuladas por um meio inadequado. Na sua visão, a condição para situação estável de paz dependia menos de tratados e acordos políticos, mas de um equilíbrio da saúde mental (LAFONTAINE 2004, p.58). O projeto de ordenação do mundo seria levado à cabo considerando a eficácia da reorganização da psicológica a partir do controle das mensagens fornecidas aos indivíduos. Assim, seria possível atingir um comportamento ideal e esperado.

A expansividade da noção de informação originada pelos estudos de Wiener e seus predecessores é, de fato, tentadora e, por vezes, pode tornar o exercício de associação elaborado por Lafontaine (2004), exagerado. Segundo ela, já estaríamos a viver naquela sociedade sonhada vivamente pelos primeiros cibernéticos do pós-Segunda Guerra Mundial: "um mundo sem fronteiras, inteiramente votado à comunicação e à troca de informações (...) tornado mais racional pelo controlo e pela gestão informacionais" (LAFONTAINE, 2004, p.15). Apesar do modelo informacional elaborado por Wiener ter caído no esque- 
cimento, a autora defendeu, insistentemente, que ele continuou a influenciar a configuração e o comportamento social contemporâneo, impondo-se como o "único horizonte paradigmático". A par dos excessos retóricos, é mister reconhecer o grau de penetração da Cibernética nos círculos circunscritos pelas teorias da informação, principalmente as ciências que se refastelam na análise social das mensagens. Do mesmo modo é mandatório admitir, em consonância com a afirmação de Martins (2005), que não há disciplina, independente do ramo a que pertence, que não tenha sido afetada nos seus variados níveis de instrumentalidade, conceitualização e na construção de modelos, em alguns casos de modo profundo e decisivo, pela constelação da informação computacional (MARTINS, 2005, p.168).

\section{O DELÍrIO de WIENER É O NOSSO: A PROMESSA DA SOCIEDAdE DA INFORMAÇÃo}

Ainda no final da década de 1940, Wiener defendia uma forte visão concentrada na liberdade da comunicação como argumento essencial para o arranjo social. Para ele, "aqueles cujo trabalho consiste em manter livres as vias de comunicação são os mesmos de quem depende sobretudo a perpetuidade ou a queda da nossa civilização" (WIENER, 1978, p. 143).

Sem dúvida, os avanços no campo da interação simbólica mediada pelo computador, sendo a Internet o seu exemplo mais profícuo para não dizer o mais rentável por ser o mais domesticado, proporcionaram uma forma, sem precedentes, de acesso à grandes volumes de informação (nas suas diversas acepções conceituais) e uma via de comunicação menos centralizada. Entretanto, o desenrolar político e a consequente entrada da informação no campo da economia transformaram o sonho wieneriano em uma catálise negativa.

No quadro das políticas afirmativas da comunicação como meio e da informação como recurso, a reafirmação do conceito de "Sociedade da Informação" nos anos de 1990 em contraposição à ideia de "Sociedade pós-industrial" representou um marco decisivo na continuidade do projeto da primeira Cibernética. A expressão, incorporada à agenda e aos documentos de instituições internacionais como a ONU, O G8 e OCDE, foi alvo de inúmeras discussões devido à carga ideológica que foi assumindo no seu processo de construção (WEBSTER, 2006, p.8). O termo integra o quadro predecessor da transformação da estrutura econômica de países como os Estados Unidos durante a desregulamentação do mercado das telecomunicações no início da década de 1950 (Schiller, 2000) um período de intensa afirmação de uma nova economia baseada na organização e na produção da informação. (May, 2003; Castells, 1993; Porat, 
1977; Drucker, 1969; Nora e Minc, 1978)Ao mesmo propósito, encontramos em Bell (1999) o reconhecimento das mudanças que a informação, entendida como theoretical knowledge, ocasionaria no tecido social ao tornar-se o eixo principal da information economy (PORAT, 1977).

Webster (2006) sugeriu interpretar a "Sociedade da Informação" a partir de seis campos: o tecnológico, o econômico, o ocupacional, o espacial, o cultural e o conhecimento. Do mesmo modo, Braman (1989) partiu da questão do papel político da informação para salientar a importância do seu enquadramento considerando quatro perspectivas: a informação como recurso; como mercadoria; como a percepção de um padrão e como uma força elementar da sociedade. Nos dois casos, fica claro o quanto a utilização da informação enquanto marcador valorativo de uma sociedade depende da decisão política que se faz (CAPURRO; HJORLAND, 2003, p.373-374; BRAMAN, 1989). Foi neste sentido que a expressão adquiriu robustez nos primeiros anos da sua utilização para justificar a desregulamentação do mercado mundial das telecomunicações a fim de resolver a saturação enfrentada pelas economias do Norte na corrida pela absorção dos seus excedentes (scHILLER, 2000).

Importante observar que as manobras politicas para afirmar a hegemonia do mercado das telecomunicações, principalmente nos Estados Unidos e alguns países desenvolvidos como a França e a Alemanha, são acompanhadas de desdobramentos retóricos orientados para versões sociológicas das transformações advindas da explosão das NTCIs. De um lado deparamo-nos com fundamentos articulados em torno da mercantilização da informação como recurso desenvolvimentista de novas e velhas economias, e por outro lado, com a elaboração de argumentos sociológicos a respeito do papel amigável das NTCIs na construção de novas alternativas para a democracia representativa, o exercício político e a formação de novas subjetividades. As interpretações sociológicas dos efeitos, sejam estes problemáticos e/ou benéficos, privilegiam, em boa parte da literatura, uma perspectiva que coloca a informação como uma força estruturadora da sociedade. Pela força legitimadora deste quadro teórico, e por efeito quase imediato, a ideia de uma sociedade orientada por uma superestrutura informacional acabou por ser definida como projeto político dos Estados. Ao mesmo tempo, a informação foi consolidada como constituinte fundamental de um novo modo de produção baseado na sua circulação em escalas globais.

Neste sentido, o projeto de socialização das NTCIs integra-se como um importante efeito do que alguns autores consideram ser a refuncionalização da bios politikos. Alguns pesquisadores chegaram a defender que a dinâmica do ambiente digital favoreceu, de modo postular e irreversível, a amplificação do espaço público, estabelecendo importantes transformações estruturais e 
operacionais no exercício da expressividade política (CASTELLS, 2007; 2005; 2003; LÉVY 1997; NEGROPONTE, 1995; WELLMAN, 2004). As novas teses, na tentativa de superar o maniqueísmo cibernético, romper com a mitologia do controle e esquecer o aparente fracasso retórico da Cibernética, providenciaram novas leituras sobre as potencialidades políticas das NTCIs, por exemplo, na proposição de uma nova ontologia da informação recomendando sua acepção como recurso social e tecnológico no processo simbólico de mediação das relações interativas no âmbito social, principalmente, no quadro de desenvolvimento econômico.

Dentre os inúmeros teóricos que debateram o tema, Castells, seguindo as profecias de McLuhan (1965) e as contribuições de Bell (1999), tornou-se um dos mais populares a celebrar a reticularidade e a heterotopia no processo de transmissão da informação através do advento da Internet como o pressuposto ideal a fim de estabelecer o projeto de Wiener: uma sociedade que comunica, interage e desenvolve-se, nesta ordem. Castells retornou aos conceitos básicos da Cibernética (a primeira e a segunda) adicionando a ideia da "rede" como base elementar da constituição do conceito de Sociedade Informacional. Ao oferecer uma leitura menos utilitarista e oposta ao paradigma da Sociedade da Informação, a sua formulação propunha uma clara diferenciação entre o "industrial" e o "informacional" a partir do estudo do surgimento de uma nova estrutura social que o autor considera ser um novo modo desenvolvimento baseado na ideia de informacionalismo (CASTELLS, 2005, p.51). A base desta estrutura é revigorada a partir da reestruturação do modo clássico de produção capitalista em que o processamento de informação, baseada em conhecimentos, tornou-se a fonte de produtividade elementar da dinâmica desta nova economia (FUCHs, 2007).

Concentrado na revolução das tecnologias da informação, a proposta de Castells (2005) é holística. Envolve desde as transformações na dinâmica capitalista tradicional (o industrialismo) até as suas repercussões na formação das identidade individuais a partir do que autor considerou ser um novo paradigma tecnológico. As transformações apontadas pelo autor fazem parte não da mudança na estrutura das atividades humanas mas na forma como estas práticas passaram a ser realizadas, ou seja, utilizando a capacidade tecnológica como fonte direta da força produtiva daquilo "que caracteriza nossa espécie como uma singularidade biológica: nossa capacidade superior de processar símbolos" (CASTELLS, 2005, p.142). Neste sentido, a perspectiva dos estudos de Castells, para além do seu caráter exemplar no processo descritivo da economia fundada pelos novos modos de produção, serviu de aporte, quase de forma contínua, para sustentar o valor social da tecnologia como 
mediadora fundamental nos processos que envolvem as trocas de informação e de conhecimento. Serviu também como subsídio para afirmar a figura do humano como representação de si a partir da metáfora de máquina comunicante (BRETON, 1992, p.125), de ser informacional (WIENER, 1978; CASTELLS, 2005) e parte imbricada num sistema coletivo de tratamento da informação (TURING, 1950; TURKLE, 2005, p.22).

$\mathrm{Na}$ apreciação de Castells, a afirmação do paradigma tecnológico da informação como tendência dominante, tanto das economias desenvolvidas como nas em desenvolvimento, é moldada por cinco características essenciais: a) a informação é a sua matéria-prima; b) a penetração das NTCIs no escopo social é inevitável porque a informação é parte integrante da ecologia humana; c) as NTCIs proporcionam a lógica das redes, única forma material de harmonizar a complexidade das relações; d) as NTCIs permitem um contexto de flexibilidade pelo sua capacidade recursiva de reorganizar os fluxos; e) a tecnologia proporciona um ambiente de intensa convergência, conduzindo as trajetórias do seu desenvolvimento como um objetivo comum às diversas disciplinas científicas e à formação de políticas públicas (CASTELLS, 2005).

O contexto que sucedeu as formulações científicas acerca do conceito de informação deram, para além da base teórica de diversificadas disciplinas, fundamento ao processo de mediação das profundas mudanças estruturais que ocorreram na economia global e na fórmula de se fazer política. No campo da política mundial, o progresso e a inovação técnica das tecnologias da informação ofereceram aos governos fortes justificativas para que os investimentos, tanto ao nível das infra-estruturas como no âmbito do desenvolvimento do pensamento científico, nomeadamente no campo da sociologia e da psicologia, fossem realizadas de forma improrrogável. Do mesmo modo, colocou sérios desafios ao campo da organização mundial do trabalho, uma área diretamente afetada pela transformação no modo de produção inaugurado pela introdução da informação como recurso laboral.

No interlúdio dos debates, a ideia de Sociedade da Informação afirmou-se como um símbolo regresso de uma sociedade ideal, potencialmente emancipatória, preconizando o desenvolvimento e a utilização ininterrupta das NTCIs como meio fundamental para satisfazer as necessidades sociais. Mais se falou dos impactos no sentido da sua instrumentalidade como recurso positivo, e menos dos efeitos corrosivos ocasionados pela fratura de campos sensíveis dos grupos sociais, historicamente, excluídos das promessas da tecnologia.

Não há dúvidas de que os efeitos e impactos da tecnociência integram o campo das subjetividades políticas em que o contexto social influencia a forma como a tecnologia é introduzida, refletindo no tipo de investimento 
que governos e empresas destinam a diferentes estratos sociais. Como é óbvio, as promessas a que muitos sociólogos e filósofos da comunicação defenderam, permaneceram obliteradas pela história econômica e política do conhecimento e da informação como recurso. Não implica dizer com isso que a tecnologia seja positiva, negativa e muito menos neutra. Ao contrário, como fez Heidegger (1977), compete ao cientista social a análise da representação subjetiva elaborada pelo discurso prometeico em torno da informação e, consequentemente, sobre os recursos materiais que dela fazem uso para, desta forma apresentar não a descrição crítica da técnica em si, mas da essência que a compõe enquanto construção política. É nesta premissa que se baseiam os discursos incisivos das políticas econômicas da informação e nas investidas do capitalismo em formatar uma economia do conhecimento apoiada na mercantilização do saber como recurso fundamental para o desenvolvimento mundial (GARCIA 2009, p.24). A premissa também serve como contraponto para a elaboração de uma sociologia das contradições fundamentada na conjugação utópica levada à cabo pela ideologia cibernética e perseguida por teorias tektópicas (MARTINS, 2011) ajustadas mais a interesses privados do que interesses, maioritariamente, universais como, outrora, imaginou Wiener.

O extenso quadro científico e sociológico pelo qual passou o conceito de Sociedade de Informação, desde os primeiros experimentos cibernéticos, seguido pelas contribuições de Turing (1950), Shannon e Weaver (1949), entre tantos outros que integram o conjunto de esforços em volta da afirmação da informação como símbolo máximo dos processos biológicos e maquínicos de comunicação, até a sua última expressão encarnada pela popularização de inúmeros objetos tecnológicos capazes de se conectarem e fazer circular diversas formas de conteúdos e conhecimentos, revela como a tecnologia, especificamente esta que faz circular bens informacionais, passou exercer influência direta na interpretação subjetiva e objetiva do mundo. A informação passou de categoria analítica da engenharia, da biologia e da filosofia tornando-se, fundamentalmente, em uma força elementar da sociedade. É sob o seu valor social que a economia tem se apoiado ao investir no seu caráter mensurável através da proclamação da utopia de um mundo calculável. Esta, que por sua vez, se transforma em utopia do dinheiro (WAIZBORT, 2000) permanecendo escamoteada pelo nivelamento democrático de uma utopia da comunicação (BRETON, 1992). Para além disso, resta salientar que a informação passou a reintegrarse socialmente e de modo expressivo como um recurso fundamental - nos processos de empowerment social. É neste sentido que a informação, considerando a expressividade da Internet e o seu caráter de força imediata de produção, tornou-se sinônimo de poder, passando a ser enquadrada como o alvo 
principal nas disputas em que o seu acesso deixa de ser público para tornar-se controlado por medidas coercitivas (leis de propriedade intelectual) e aparatos técnicos (como o caso dos Digital Rights Management).

A condução do conceito de informação para o campo da legislação adianta um novo desafio político ao colocar em confronto os fundamentos humanistas da liberdade de expressão, e a natureza imaterial da informação e os interesses capitalistas na proteção e na restrição do seu livre acesso como um caminho exclusivo de manutenção do mercado, uma manobra que é resultado, conforme salientou Burawoy (2005), intrínseco às políticas neoliberais de privatização da vida.

A promessa de uma sociedade articulada pela livre permuta de informação, em constante processo de retroalimentação e, desta forma, em intensa perfomance homeostática, parece sucumbir aos modos de tratamento exclusivo da informação como mercadoria, desta forma sendo submetida à paralelizações advindas dos conceitos clássicos do capitalismo industrial.

Este contexto revela um importante antagonismo da economia baseada na informação - entendida como conhecimento, como uma forma de aquisição, produção e difusão do saber. Se ela é considerada como bem público (open source), sua inclusão na categoria de mercadoria limita a sua função heurística ao tornar-se um produto submetido à noção de propriedade intelectual. Restrita também se torna quando as NTCIs passam a integrar as políticas informacionais. Se de um lado, elas figuram como potenciais instrumentos para consecução de novas formas do exercício participativo e democrático, por outro, a mesma potencialidade é obliterada por meio da suas instrumentalização como redes de vigilância e controle.

\section{REFERÊNCIAS BIBLIOGRÁFICAS}

ABRIL, G. (1997). Teoría General de la Informaçión. Madrid: Cátedra.

ARENDT, H. (2001). A condição humana. Lisboa: Relógio D’Água.

ALMOND, G.; \& POWELL Jr., G.B.(1966). Comparative politics: adevelopmental approach. Boston: Little Brown.

BATESON, G. (2006). Naven : um esboço dos problemas sugeridos por um retrato compósito, realizado a partir de três perspectivas, da cultura de uma tribo da Nova Guiné. 2. ED. São Paulo : Editora da Universidade de São Paulo.

BELL, D. (1999). The Coming of Post-Industrial Society: A Venture in Social Forecasting. New York: Basic Books.

BRAMAN, S. (1989). Defining information: An approach for policymakers. Telecommunications Policy, N.13, pp. 233-242. 
BRETON, P. (1992). A Utopia da Comunicação. Colecção Epistemologia e Sociedade. Lisboa: Instituto Piaget.

(1995). À imagem do homem: Do Golem às criaturas virtuais. Lisboa: Instituto Piaget. (1997). A explosão da comunicação. Lisboa: Bizâncio.

BUCKLEY, W. (1971). A sociologia e a moderna teoria dos sistemas. São Paulo: Cultrix.

BURAWOY, M. (2005). For Public Socioloy. American Sociological Review, n.70, pp. 4-28.

CABALLERO, F.S. (1999). Elementos de teoría de la información. Alcalá de Guadaira, Sevilla: Editorial Mad.

CAPURRO, R.; HJØRLAND, B. (2003). The Concept of Information. Annual Review of Information Science and Technology, n. 37. Theorizing Information and Information Use, pp. 343-411.

CAREY, J.W. (1989). Communication as Culture: Essays on Media and Society. Psychology Press.

CASTELLS, M. (1993). The Informational Economy and the New International Division of Labor. In CARNOY, M.; CASTESLLS, M.; COHEN, S.S., (ORGS.). The New Global Economy in the information age: Reflections on our changing world. Pennsylvania: The Pennsylvania State University Press. (2003). Internet e Sociedade em Rede. In De MORAES, D. (ORG.). Por uma outra Globalização: mídia, mundialização cultural e poder. Rio de Janeiro: Record, pp. 255-287

(2005). A Sociedade em Rede. 8a ED. vol. 1. Rio de Janeiro: Paz e Terra. (2007). A galáxia da Internet: Reflexões sobre Internet, Negócios $e$ Sociedade. 2a ED. Lisboa: Fundação Calouste Gulbenkian.

CONWAY, F.; SIEGELMAN, J. (2005). Dark Hero of the Information Age: In search of Norbert Wiener the father of cybernetics. New York: Basic Books.

DANTAS, M. (1999) Capitalismo na Era das Redes: trabalho, informação, valor no ciclo da comunicação produtiva. In LASTRES, H.; ALBAGI, S. Informação e globalização na era do conhecimento. Rio de Janeiro: Editora Campus, pp. 216261.

2006. "Informação como trabalho e como valor". Revista da

Sociedade Brasileira de Economia Política, no 19, pp. 44-72.

DESCARTES, R. (1980). O Discurso do Método. Lisboa: Sá da Costa Editora.

DRUCKER, P. (1969). The Age of Discontinuity: Guidelines to our Changing Society. London: Cox \& Wyman Ltd.

EASTON, D. (1968). Um Teoria da Análise Política. (TRAD. Gilberto Velho). Rio de Janeiro: Zahar Editores. 
ECO, U. (1991). Tratado geral de semiótica. São Paulo: Perspectiva.

ELLUL, J. (1980). The Technological System. New York: The Continuum Publishing Corporation.

FERKISS, V. (1980). Technology and Culture: Gnosticism, Naturalism and Incarnational Integration. Cross Currents 30 (1), pp. 13-26.

FLICHY, P. (2008). The Internet Imaginaire. Cambridge/London: The MIT Press.

FLORIDI, L. (2010). Information: A Very Short Introduction. New York: Oxford University Press.

FUCHS, C. (2007). Informationalism. In Encyclopedia of Governance. London: Sage Publications. pp. 446-448.

FURTADO, J.A. (2012). Uma cultura da informação para o universo digital. Lisboa: Fundação Francisco Manuel dos Santos.

GARCIA, J.L. (2009). Introdução aos estudos dos jornalistas portugueses: Os jornalistas e as contradições do capitalismo jornalístico no limiar do século XXI. In Estudos sobre os Jornalistas Portugueses: Metamorfoses e encruzilhadas no limiar do século XXI. Lisboa: ICS. Imprensa de Ciências Sociais, pp. 23-46.

GEROVITCH, S. (2002). From Newspeak to Cyberspeak: A History of Soviet Cybernetics. Massachusetts: MIT Press.

GOFFMAN, E. (1972). Encounters : two studies in the sociology of interaction. London: Allen Lane The Penguin Press.

HABERMAS, J. (2009). Técnica e ciência como “ideologia”. Lisboa: Edições 70.

HARRIES-JONES, P. (1991). Making knowledge count: advocacy and social science. McGill Queens Univ.

(1995). A recursive vision: Ecological understanding and Gregory Bateson. Univers of Toronto Pr.

HEIDEGGER, M. (1977). The question concerning technology. New York: Harper.

HEIMS, S. J. 1991. The Cybernetics Group, 1946-1953. Constructing a Social Science for Postwar America. Cambridge, Massachusetts: The MIT Press.

DEUSCH, K.W. (1963). The Nerves of Government. New York: The Free Press of Glencoe.

KIM, J.H. (2004). Cibernética, ciborgues e ciberespaço: notas sobre as origens da cibernética e sua reinvenção cultural. Horizontes antropológicos, N.10 (21), pp. 199-219.

LAFONTAINE, C. (2004). O Império Cibernético: Das Máquinas de Pensar ao Pensamento Máquina. Epistemologia e Sociedade 249. Lisboa: Instituto Piaget.

LAING, R.D. (1976). The Divided Self.New York. Harmondsworth: Penguin.

LASSWELL, H.D. (1978). A estrutura e a função da comunicação na sociedade. In: COHN, G. (oRg.). Comunicação e indústria cultural. São Paulo: Companhia Editora Nacional, pp. 105-117. 
LAZARSFELD, P.; MERTON, R.K.(1990). Comunicação de Massa, Gosto Popular e a Organização da Ação Social. LIMA, L.C. (org.). Teoria da Cultura de Massa (4a), pp. 101-127.

LAZARSFELD, P.; BERELSON, B.; GAUDET, H. (1944) The People's choice: How the voter makes up his mind in a presidential campaign. New York: Columbia University Press.

LÉVI-STRAUSS, C. (1963). Structural anthropology. vol. 2. New York: Basic Books.

(1969). The elementary structures of kinship. vol. 340. London: Eyre and Spottiswoode.

LÉVY, P. (1997). Collective Intelligence: Mankind's Emerging World in Cyberspace. Cambridge, Mass.: Perseus Books.

MARTINS, H. (1993). Hehel, Texas: Issues in the Philosophy and Sociology of Technology. In Knowledge and Passion: Essays in Sociology and Social Theory in Honour of John Rex. New York: I.B.Tauris. pp.226-249. (2011). Experimentum humanum civilização tecnológica e condição humana. Mediações. Lisboa: Relógio d’Água.

MARX, L. (2000). The Machine in the Garden Technology and the Pastoral Ideal in America. New York: Oxford University Press.

MATTELART, A. (2002). História da sociedade da informação. São Paulo: Loyola. (2000). A globalização da comunicação. Bauru, SP: EDUSC. (1999). A mundialização da comunicação. Economia e política 49. Lisboa: Instituto Piaget. (1994). A Invenção da Comunicação. Colecção Epistemologia e Sociedade. Lisboa: Instituto Piaget. (1991). Comunicação-mundo: Histórias das Ideias e das Estratégias. Lisboa: Instituto Piaget.

MATTElaRT, A.; MATTlelaRT, M. (2002). História das Teorias da Comunicação. Lisboa: Campo das Letras.

MATURANA, H.; VARELA, F. (1995). A árvore do conhecimento: As bases biológicas do entendimento humano. Campinas: Psy II.

MAY, C. (2003). The Information Society: A sceptical view. Malden: Blackwell Publishing.

McQUAIL, D. (2003). Teoria da Comunicação de Massas. 1a ED. Lisboa: Fundação Calouste Gulbenkian.

McLUHAN, M. (1965). Understanding Media: The Extensions of Man. New York: McGraw-Hill.

MORE, T. (1997). A Utopia. Porto Alegre: L\&PM. 
MUSSO, P. (2006). Ciberespaço, figura reticular da utopia tecnológica. In De MORAES, D. (org.). Sociedade Midiatizada. Rio de Janeiro: Mauad, pp.191-224.

NEGROPONTE, N. (1995). Being Digital. London: Hodder and Stoughton.

NORA, S.; MINC, A. (1978). L'informatisation de la socieété. Politique 92. Paris: Éditions du Seuil.

PAINE, R. (1976). Two modes of exchange and mediation. Transaction and Meaning, Philadelphia: Institute for the Study of Human Issues, pp. 63-86.

PFOHL, S. (2001). O delírio cibernético de Norbert Wiener. Revista FAMECOS, n.14, pp.105-121.

PORAT, M.U. (1977). The Information Economy: Definition and Measurement. Washington: Office of Telecommunications.

RAPPAPORT, R.A. (1968). Pigs for the ancestors: ritual in the ecology of a New Guinea people. New Haven: Yale University Press.

RAPPORT, N.; OVERING, J. (2000). Social and cultural anthropology: the key concepts. Psychology Press.

SCHILLER, D. (1988). How to Think About Information. In MOSCO, V.; WASKO, J. The Political Economy of Information. London: The University of Wisconsin Press, pp. 27-43.

(2000). Digital capitalism: Networking the global market system. Massachussets, London: The MIT Press.

(2007). How to Think About Information. Urbana/Chicago: University of Illinois Press.

SERRA, P. (2007). Manual de Teoria da Comuniacação. Estudos em Comunicação. Covilhã: Universidade da Beira Interior.

SFEZ, L. (1993). Cybernétique. Dictionnaire critique de la communication. Paris: PUF.

SHANNON, C.E.; WEAVER, W. (1949). The Mathematical Theory of Communication. Urbana e Chicago: University of Illinois Press.

SILVA, P. (2007). Cibernética: Onde os reinos se fundem. Vila Nova de Famalicão: Quasi Edições.

STANLEY, M. (1978). The Techological Conscience: Survival and Dignity in an Age of Expertise. London: The Free Press.

STRATHERN, M. (1990). Partial connections. Savage, Md: RowmanLittefield.

TOFFLER, A. (1989). The Third Wave. New York: Bantam Books.

TURING, A.M. 1950. Computing Machinery and Intelligence. Mind 59 (236). New Series, pp.433-460. 
TURKLE, S. (2005). The second self: computers and the human spirit. 20a ED. Cambridge: The MIT Press. (2011). Alone Together: Why we expect more from technology and less from each other. New York: Basic Books.

VON FOERSTER, H. (1950). Cybernetics: circular causal, and feedback mechanisms in biological and social systems. Transactions of the Sixth Conference, March 24-25. New York: Josiah Macy Jr. Foundation.

(1951). Cybernetics: circular causal, and feedback mechanisms in biological and social systems. Transactions of the Seventh Conference, March 23-22. New York: Josiah Macy Jr. Foundation.

(1952). Cybernetics: circular causal, and feedback mechanisms in biological and social systems. Transactions of the Eighth Conference, March 15-16. New York: Josiah Macy Jr. Foundation.

(1953). Cybernetics: circular causal, and feedback mechanisms in biological and social systems. Transactions of the Ninth Conference, March 20-21. New York: Josiah Macy Jr. Foundation.

(1955). Cybernetics: circular causal, and feedback mechanisms in biological and social systems. Transactions of the Tenth Conference, April 22-24. New York: Josiah Macy Jr. Foundation.

WAIZBORT, L. (2000). As Aventuras de Georg Simmel. São Paulo: Editora 34.

WIENER, N. (1948). Cybernetics or control and communication in the animal and the machine. New York, London: The MIT Press e John Wiley \& Sons.

(1961). Cybernetics or control and communication in the animal and the machine. 2nd ED. Cambridge: M.I.T.

(1978). Cibernética e sociedade o uso humano de seres humanos. 5a ED. São Paulo: Cultrix.

WIENER, N.; ROSENBLUETH, A.; BIGELOW, J. (1943). Behavior, Purpose and Teleology. Philosophy of Science 10, pp. 18-24.

WEAVER, W. (1949). The Mathematics of Communication. Scientific American n.181 (1), pp. 11-15.

WEBSTER, F. (2006). Theories of the Information Society. 3a ED. New York: Routledge.

WELLMAN, B. (1999). Living Networked in a Wired World. Disponível em: http/www.chass.utoronto.ca/ wellman. (Última consulta: 01 de setembro de 2009).

(2004). The Glocal Village: Internet and Community. The Arts $\theta$ Science Review. v.1, n.1. University of Toronto, pp. 26-29. Disponível em: http/www.chass.utoronto.ca/ wellman. (Última consulta: 01 de setembro de 2009). 
A RETÓRICA DA ILUSÃO: ESBOÇOS DA CIBERNÉTICA NO RASTRO DA SOCIEDADE DA INFORMAÇÃO

WHEELER, J. A. (1990). Information, physics, quantum: The search for links. In ZUREK, W., Complexity, Entropy, and the Physics of Information. Redwood City, California: Addison-Wesley, pp. 309-336.

WOLF, M. (1987). Teorias da Comunicação. Lisboa: Editorial Presença. 